\title{
Survival analyses of symbionts isolated from Endocarpon pusillum Hedwig to desiccation and starvation stress
}

\author{
ZHANG Tao ${ }^{1,2} \&$ WEI JiangChun ${ }^{1 *}$ \\ ${ }^{1}$ Key Laboratory of Systematic Mycology \& Lichenology, Institute of Microbiology, Chinese Academy of Sciences, Beijing 100101, China; \\ ${ }^{2}$ Graduate University of Chinese Academy of Sciences, Beijing 100049, China
}

Received March 20, 2009; accepted June 28, 2009

\begin{abstract}
This work deals with the survival analyses of the symbionts isolated from the lichen E. pusillum under desiccation and starvation stress. The mycobiont of the symbionts was under the desiccation in combination with starvation stress, and under starvation stress alone as well. The phycobiont of the symbionts was under desiccation stress alone. The experiments were detected by means of the biomass size, weight and cell density, deformity of the hyphae and cells, and metabolic activity through SEM (scanning electron microscopy), TEM (transmission electron microscopy), FM (fluorescence microscopy), spectrophotometry, and FCM (flow cytometry). The results show that the mycobiont can survive for seven months under desiccation stress in combination with starvation stress, and for eight months under starvation stress alone. The phycobiont can survive for two months under desiccation stress. It can provide a scientific basis for further research of the reproduction biology of lichens and arid desert biocarpet engineering to fix sand and carbon.
\end{abstract}

lichens, mycobiont, phycobiont, SEM, TEM, FM, FCM, reproduction, biocarpet

Citation: Zhang T, Wei J C. Survival analyses of symbionts isolated from Endocarpon pusillum Hedwig to desiccation and starvation stress. Sci China Life Sci, 2011, 54: 480-489, doi: 10.1007/s11427-011-4164-z

One of the central challenges of adversity-resistance biology is to understand the responses and adaptations of desert species to arid conditions. A lichen is a life-support system composed of a specific fungus (mycobiont) and a corresponding alga (phycobiont) or a cyanobacterium (cyanobiont) in an unique symbiotic relationship. "Their unique symbiotic relationship with algae has enabled these fungi to colonize and flourish in a wide range of habitats from the Antarctic continent to the rain forests of the tropics. Their ecological success in so many types of habitats depends on a number of unique structural and functional adaptations that are only now beginning to be generally appreciated by mycologists and microbiologists" [1].

Lichens are some of the most drought-resistant organisms; this characteristic has been extensively studied. In

*Corresponding author (email: weijc2004@126.com) particular, levels of resistance to desiccation have been assessed using photosynthesis or respiration as indicators. Most of lichens are able to survive desiccation for several months [2-4], and a few species can survive for more than a year [4,5]. In reviewing previous studies, Lange [4] concluded that there was a general correlation between water conditions within the habitat and desiccation tolerance, i.e., the drier the habitat, the greater the desiccation tolerance of the lichen.

Although the length of the desiccation period that lichens can survive is well documented, this information is still limited for isolated symbionts. Ahmadjian and Hale [6] reviewed the previous studies of desiccation resistance of isolated symbionts, and indicated that the isolated mycobionts could survive desiccation for five weeks (three species) or six weeks (seven species), while the isolated phycobionts could survive for six weeks (13 species) or 41 weeks (two 
species).

With respect to the symbiotic relationship in lichens, the mycobionts must obtain nutrients provided by the specific phycobionts and then establish the true symbiosis. Schaper and Ott [7] found that the establishment of initial contact between mycobiont and phycobiont (e.g., formation of haustoria-like structures with hyphae branching and enveloping the phycobiont surface) appeared to take about six weeks. Mycobionts, therefore, can probably survive starvation for some time before obtaining nutrients from phycobionts. However, little is known about the limits of survival of the isolated mycobionts subjected to starvation stress.

Some non-lichenized fungi and algae are also known to be desiccation-tolerant. Microcolonial rock fungi (MCF), for example, are known to survive desiccation for 32 [8] or $56 \mathrm{~d}$ [9]. The alga, Chlorella vulgaris Beijerinck, remained viable in desiccated state for about $30 \mathrm{~d}$ [10], and five algae, Microcoleus chthonoplastes Thuret, Phormidium bohneri Schmidle, Rhizoclonium crassipellitum West \& G. S. West, Lyngbya mesotricha Skuja and Scytonema millei Bornet, were observed to survive from 0.5 to 2 months [11].

Desert lichens are ecologically significant because they weaken windstorm by fixing sand and dust, and weaken global warming by fixing carbon dioxide from the atmosphere through photosynthesis. E. pusillum is a dominant species that is widespread in the arid desert regions of northern China. We study the stress tolerance of symbionts isolated from E. pusillum, which is a previous research of the arid desert biocarpet engineering to improve environments and the screening of drought-resistant genes from lichen symbionts.

\section{Materials and methods}

\subsection{Isolation and identification of the symbionts}

The lichen E. pusillum was collected from Shapotou Desert Experimental Research Station $\left(37^{\circ} 32^{\prime} \mathrm{N}, 105^{\circ} 02^{\prime} \mathrm{E}\right.$; alt. $1340 \mathrm{~m}$; mean annual precipitation in this area is $186 \mathrm{~mm}$, and annual potential evaporation is $2800 \mathrm{~mm}$ [12]). Symbionts within E. pusillum (Figure 1A) were isolated by spore discharge [13] from the perithecia of the same lichen thalli. The ascospores of the mycobiont were synchronously discharged together with the hymenial algal cells onto the surface of $1.5 \%$ water agar in a Petri dish. When the ascospores germinated, the germinated spores and small algal colonies (Figure 1C) were transferred to tubes containing potato dextrose agar (PDA). A colony was formed from the germinated ascospores and the hymenial algal cells (Figure 1D). A small piece of the mycelia and some of the alga were then transferred to the tubes containing PDA and Bold's Basal Medium (BBM) for cultivation, respectively.

Analyses of morphology and molecular systematics were used to confirm that the isolated fungi and algae were sym-
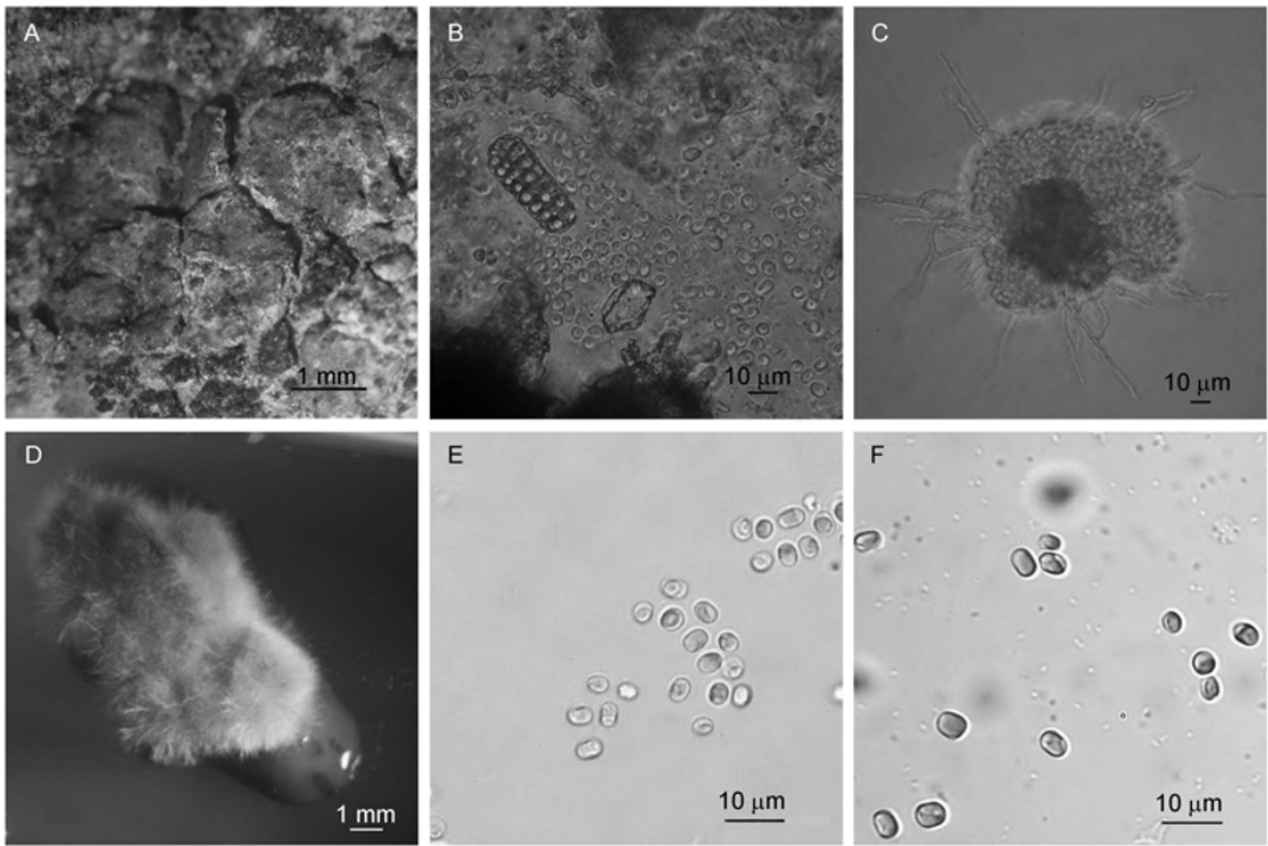

Figure 1 The lichen E. pusillum and its symbionts. A, The habit of E. pusillum. B, Ascospores with hymenial algal cells within a perithecium. C, Germinating ascospores with numerous algal cells ejected from a perithecium. D, A colony formed from the discharged ascospores and the hymenial algal cells for two months after being transferred. E, Algal cells from E. pusillum in the liquid BBM. F, Algal cells of D. chodatii (UTEX No. 1177) in liquid BBM. 
bionts within lichen $E$. pusillum rather than contamination.

Total DNA was extracted using a modified CTAB method [14] from samples as follows: (i) Mycobiont: the mycobiont isolated from E. pusillum, E. pusillum and out-group species E. crystallinum J. C. Wei \& J. Yang. Sequence data for other out-group lichen species were downloaded from GenBank (Table 1); (ii) Phycobiont: the phycobiont isolated from E. pusillum and D. chodatii (Table $2)$. Sequence data for out-group algal species were down-loaded from GenBank.

The ITS region (including ITS1, 5.8S rDNA and ITS2) from lichen and algal species was analyzed. Primers ITS1 and ITS4 [15] were used for PCR amplification of the mycobiont. Primers nr-SSU-1780-5'-algal and nr-LSU-00123 '-algal [16] were used for PCR amplification of the phycobiont.

PCR products were purified and sequenced by Genewiz Inc. (Beijing, China). Phylogenetic trees were constructed using neighbor-joining method [17].

Voucher specimens of E. pusillum and E. crystallinum were deposited in Herbarium Mycologicum Academiae Sinicae-Lichenes (HMAS-L). The alga $D$. chodatii obtained from the Culture Collection of Algae at the University of Texas at Austin (UTEX) was deposited in the Laboratory of Lichen Biology at the Institute of Microbiology, Chinese Academy of Sciences.

\subsection{Experimental design for survival analyses of sym- bionts}

Colonies of the isolated mycobiont were transferred into liquid PDA. After two months, the liquid suspension was passed through a sterilized stainless steel filter with a 500- $\mu \mathrm{m}$ mesh, and mycelial pellets were collected. These pellets (diameter $\approx 1 \mathrm{~mm}$ ) were transferred directly onto the plastic bases of Petri dishes (35 $\mathrm{mm}$ in diameter) without nutrients and water, and placed in desiccators over fused silica gel (relative humidity $\leqslant 10 \%$, room temperature $20-27^{\circ} \mathrm{C}$, and room light intensity). Samples were thus subjected to the stress conditions in combination with desiccation and starvation. Other mycelial pellets of the isolated mycobiont were transferred into 50-mL Erlenmeyer flasks containing sterile distilled water and placed in the laboratory (room temperature $20-27^{\circ} \mathrm{C}$ and room light intensity) to subject the samples to starvation stress alone.

Samples were examined and measured at regular time, using colony size and weight measurement (CSM \& CWM; three replications), scanning electron microscopy (SEM, Quanta 200, FEI Co.), transmission electron microscopy (TEM, JEM-1400, JEOL Ltd.) and florescence microscopy (FM).

FM was used to determine whether the mycobiont cells were metabolically active. In metabolically active cells, fluorescein diacetate (FDA) is converted into green fluorescent fluorescein. The hyphae of the isolated mycobiont were suspended in a working solution of FDA (Merck, CB343209; stock solutions: $1 \mathrm{mg}$ FDA in $1 \mathrm{~mL}$ acetone; working solutions: $1 \mu \mathrm{L}$ stock FDA in $4 \mathrm{~mL}$ deionized water), and incubated for $30 \mathrm{~min}$ at room temperature. The green fluorescence of the mycobiont cells was examined using a fluorescence microscope (Axio imager A1, ZEISS Co.) with an excitation filter of $450-490 \mathrm{~nm}$ and a barrier filter of $520 \mathrm{~nm}$.

Colonies of the isolated phycobiont were transferred into liquid BBM. After one month, $1 \mathrm{~mL}$ of phycobiont cells suspension $\left(\approx 6.5 \times 10^{6}\right.$ cells $\left.\mathrm{mL}^{-1}\right)$ was transferred by a sterilized transfer pipette onto the plastic bases of Petri dishes (35 $\mathrm{mm}$ in diameter) without medium and water, and they were placed in desiccators over fused silica gel (relative humidity $\leqslant 10 \%$, room temperature $20-27^{\circ} \mathrm{C}$, and room

Table 1 Lichen species examined and sequenced (in bold text) and downloaded from GenBank

\begin{tabular}{ccc}
\hline Species & Source & GenBank accession number \\
\hline Mycobiont isolated from $\boldsymbol{E}$. pusillum & Shapotou & HM237333 \\
E. pusillum & Shapotou, HMAS-L & HM237334 \\
E. crystallinum & Shapotou, HMAS-L & DQ826735 \\
E. pallidulum (Nyl.) Nyl. & GenBank & GenBank \\
Verrucaria viridula (Schrad.) Ach. & DQ553510 \\
\hline
\end{tabular}

Table 2 Algal species examined and sequenced (in bold text) and downloaded from GenBank

\begin{tabular}{ccc}
\hline Species & Source & GenBank accession number \\
\hline Phycobiont isolated from E. pusillum & Shapotou & HM237336 \\
Phycobiont in E. pusillum & Shapotou & HM237335 \\
D. chodatii & University of Texas (UTEX No. 1177) & HQ129931 \\
Stichococcus bacillaris Nägeli & GenBank & AJ431678 \\
S. mirabilis Lagerheim & GenBank & AJ431679 \\
C. vulgaris & GenBank & FM205855 \\
\hline
\end{tabular}


light intensity) to subject the samples to desiccation stress.

Samples were examined and measured at regular intervals by measurement of naked eyes (MNE) and cell density measurement (CDM) using a spectrophotometer (UV-2800 UV/Vis, Unico Shanghai Instruments Co.; three replications). SEM, TEM and flow cytometry (FCM) were also used to examine the samples.

FCM was used to determine whether the phycobiont cells were metabolically active when subjected to desiccation. For FDA staining of the isolated phycobiont, $1 \mu \mathrm{L}$ of the FDA stock solutions $\left(1 \mathrm{mg} \mathrm{mL} \mathrm{m}^{-1}\right.$ in acetone) was mixed with $1 \mathrm{~mL}$ of phycobiont cells suspension and then incubated for $30 \mathrm{~min}$ at room temperature. The green fluorescence of phycobiont cells was examined using a flow cytometer (FCM, BD FACSAria, Becton Dickinson Co.). Excitation at $488 \mathrm{~nm}$ was induced by an argon laser and the emission was confined by a 515-545 nm interference filter [18]. BD FACSDiVa software (Becton Dickinson Co.) was used for instrument control and sample analysis.

\subsection{Statistical analysis}

Data were analyzed using one-way analysis of variance (ANOVA). Significant differences were determined by Duncan's multiple range test $(P<0.05)$. All statistical analyses were performed using SPSS 15.0 statistic software (SPSS Inc., USA).

\section{Results and discussion}

\subsection{Identification of the symbionts}

Ascospores of the mycobiont isolated from E. pusillum were morphologically identical to those within a perithecium of E. pusillum (Figure 1B).

The phylogenetic tree (Figure 2) shows that the mycobionts isolated from E. pusillum (HM237333) and E. pusillum (HM237334) form a monophyletic group with high bootstrap support (100\%). A large genetic distance was found between this clade and the outgroup, including E. pallidulum (DQ826735; bootstrap value=58\%), E. crystallinum (HM237332; bootstrap value $<50 \%$ ) and Verrucaria viridula (EU553510; bootstrap value $<50 \%$ ). This indicates the isolated mycobiont is the true mycobiont of E. pusillum.

The phylogenetic tree (Figure 3) shows that the phycobiont isolated from the E. pusillum (HM237336), the phycobiont in the E. pusillum (HM237335) and D. chodatii (HQ129931) form a monophyletic group with high bootstrap support (100\%). A large genetic distance was found between this clade and the outgroup, including S. bacillaris (AJ431678; bootstrap value=54\%), S. mirabilis (AJ431679; bootstrap value $<50 \%$ ) and $C$. vulgaris (FM205855; bootstrap value $<50 \%)$. This indicates the isolated phycobiont is the true phycobiont of E. pusillum, and the same as Diplosphaera chodatii Bialosuknia [19] (三Stichococcus chodatii (Bialosuknia) Heering [20]=Stichococcus diplosphaera Chodat [21]), and belongs to Chaetophoraceae (Chlorophyta).

\subsection{Survival analyses of the mycobiont}

\subsubsection{Colony size and weight measurement of the myco- biont}

The growth capability of the isolated mycobiont was determined by CSM (Figures 4 and 5, Table 3) and CWM (Figure 6).

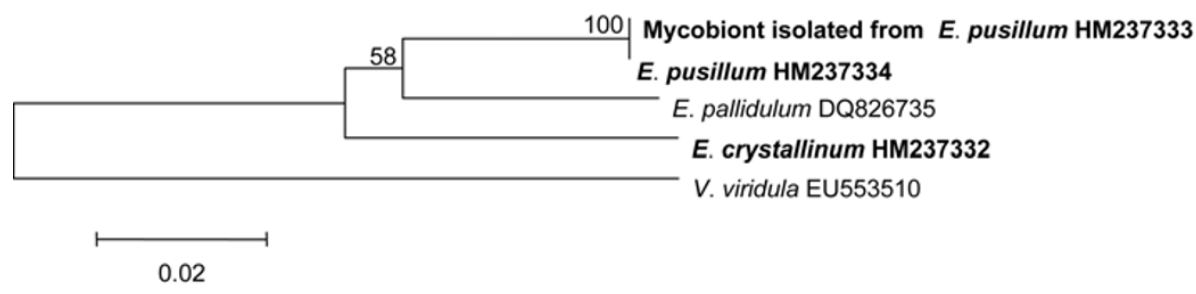

Figure 2 NJ tree based on rDNA ITS sequences of mycobionts. Bootstraps values greater than $50 \%$ are indicated. The scale bar represents the Kimura-2-parameter genetic distance. Samples in bold were examined by the authors.

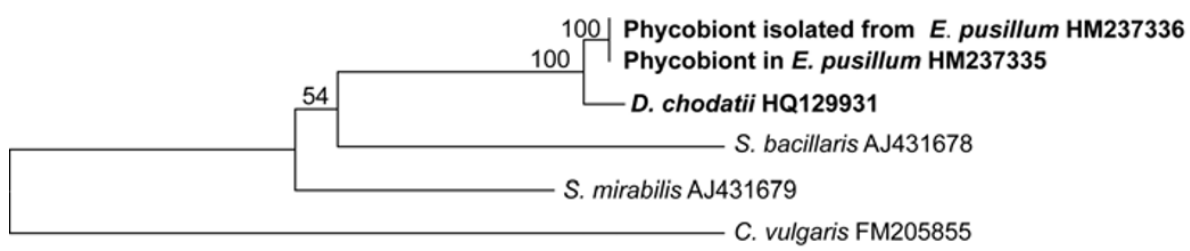

0.05

Figure 3 NJ tree based on rDNA ITS sequences of phycobionts. Bootstraps values greater than 50\% are indicated. The scale bar represents the Kimura-2-parameter genetic distance. Samples in bold were examined by the authors. 

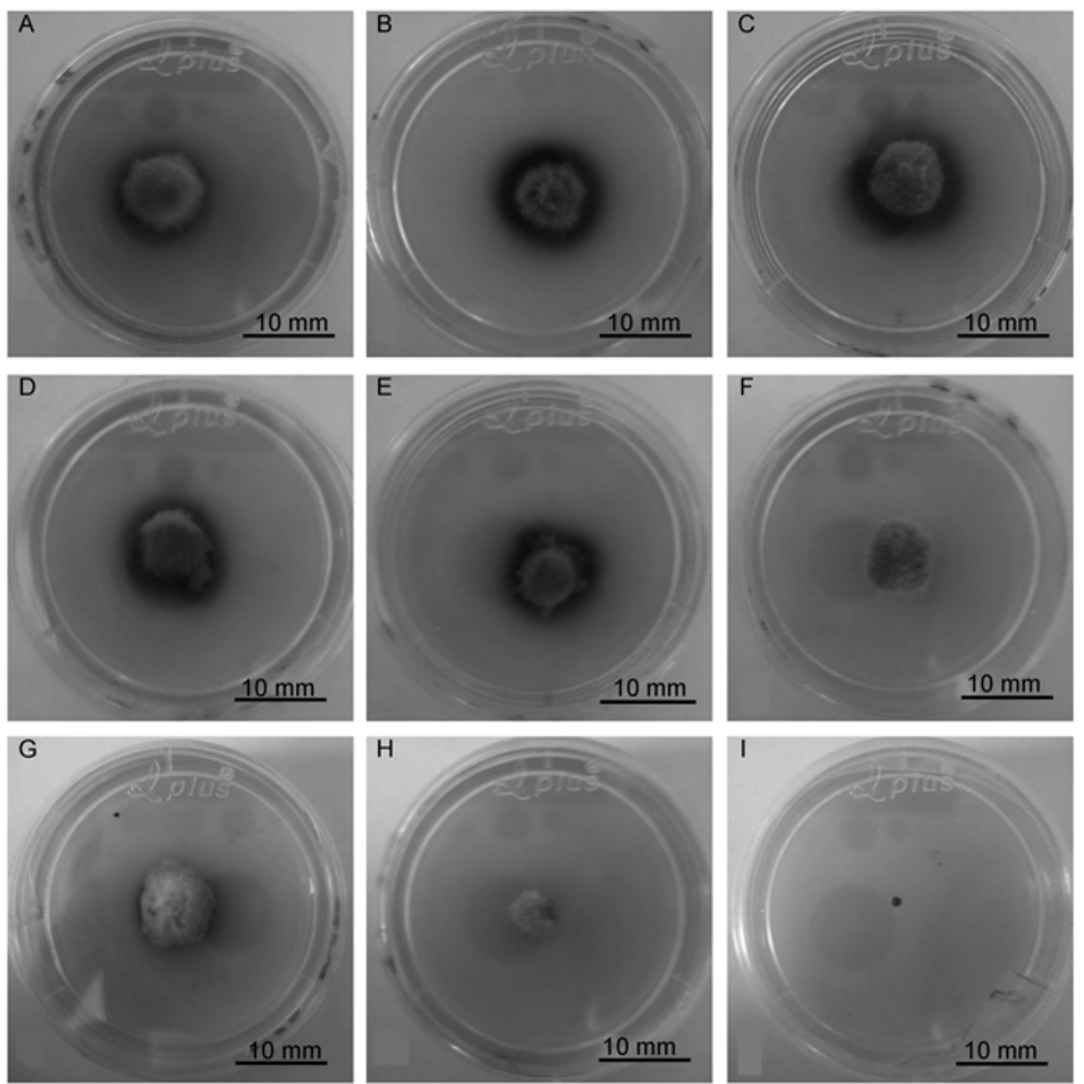

Figure 4 Colonies of the isolated mycobiont grown on PDA for two months after transfer from combined desiccation and starvation. A, Control. B, Transfer after one month of stress. C, After two months. D, After three months. E, After four months. F, After five months. G, After six months. H, After seven months. I, After eight months.
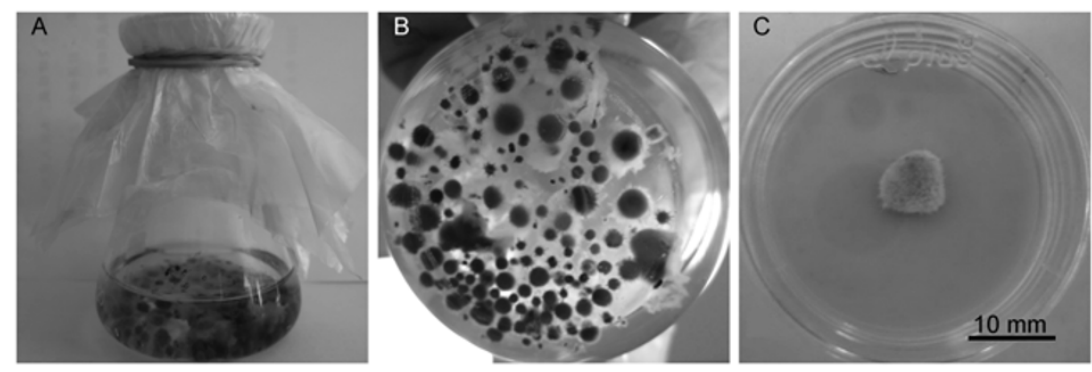

Figure 5 Growth of the isolated mycobiont under starvation stress. A and B, After eight months of growth in the 50-mL Erlenmeyer flask containing sterile distilled water. C, Colony of the isolated mycobiont on PDA in the Petri dish transferred from the Erlenmeyer flask after eight months.

The CSM of the isolated mycobiont growing on PDA for two months after transfer from stress conditions shows that the colonies are $8-9 \mathrm{~mm}$ in diameter after stress treatment for 1-6 months (Figure 4B-G, Table 3), and $5 \mathrm{~mm}$ in diameter after stress for seven months (Figure $4 \mathrm{H}$, Table 3), and $0 \mathrm{~mm}$ in diameter after stress for eight months (Figure 4I, Table 3).

The colony grown on PDA in the Petri dish for two months after transfer from an Erlenmeyer flask was $8 \mathrm{~mm}$ in diameter (Figure 5C).

The result of CWM (Figure 6) was basically consistent with that of CSM (Figures 4 and 5, Table 3). It shows that the mycobiont of E. pusillum subjected to desiccation stress
Table 3 Colony size of isolated mycobiont grown on PDA for two months after transfer from that under the stress conditions in combination with desiccation and starvation

\begin{tabular}{cc}
\hline Periods of stress treatment & Colony size (diameter) \\
\hline A: control without stress treatment & $9 \mathrm{~mm}$ \\
B: one month & $8 \mathrm{~mm}$ \\
C: two months & $9 \mathrm{~mm}$ \\
D: three months & $8 \mathrm{~mm}$ \\
E: four months & $7.5 \mathrm{~mm}$ \\
F: five months & $8 \mathrm{~mm}$ \\
G: six months & $8 \mathrm{~mm}$ \\
H: seven months & $5 \mathrm{~mm}$ \\
I: eight months & $0 \mathrm{~mm}$ \\
\hline
\end{tabular}




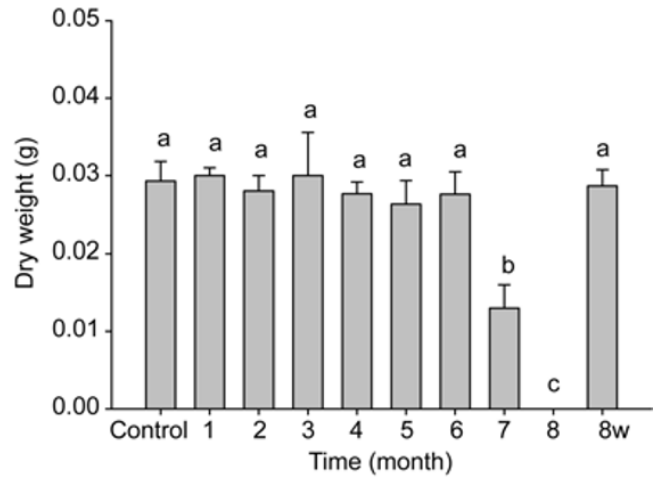

Figure 6 Dry weight of the colonies of the isolated mycobiont grown on PDA for two months. Data are presented as mean \pm SD. Three replicates were analyzed for each. From left to right the columns represent control, mycobiont under combined desiccation and starvation for 1-8 months and mycobiont in water alone for eight months $(8 \mathrm{w})$. a, well growth; b, moderate growth; c, death. in combination with starvation stress could maintain normal viability after six months, maintain half viability after seven months and lose viability after eight months. Therefore, its survival time limit under desiccation stress in combination with starvation stress was seven months. Additionally, the isolated mycobiont subjected to starvation alone could maintain normal viability after eight months, but its survival time limit under starvation alone has yet to be explored further.

\subsubsection{Comparative morphological analysis of the myco- biont}

The morphology and anatomy of the isolated mycobiont were observed using SEM and TEM (Figure 7).

The hyphae subjected to three months of combined desiccation and starvation were deformed, but the stereoscopic hyphal contour was still visible (Figure 7D). Hyphae had
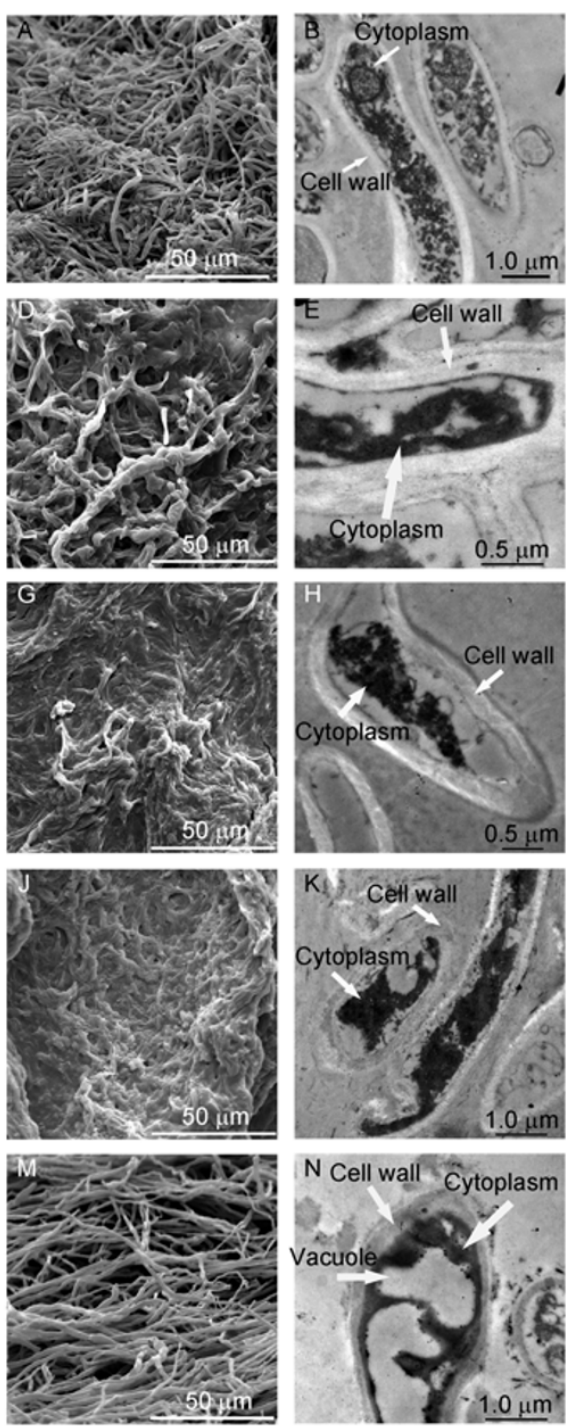
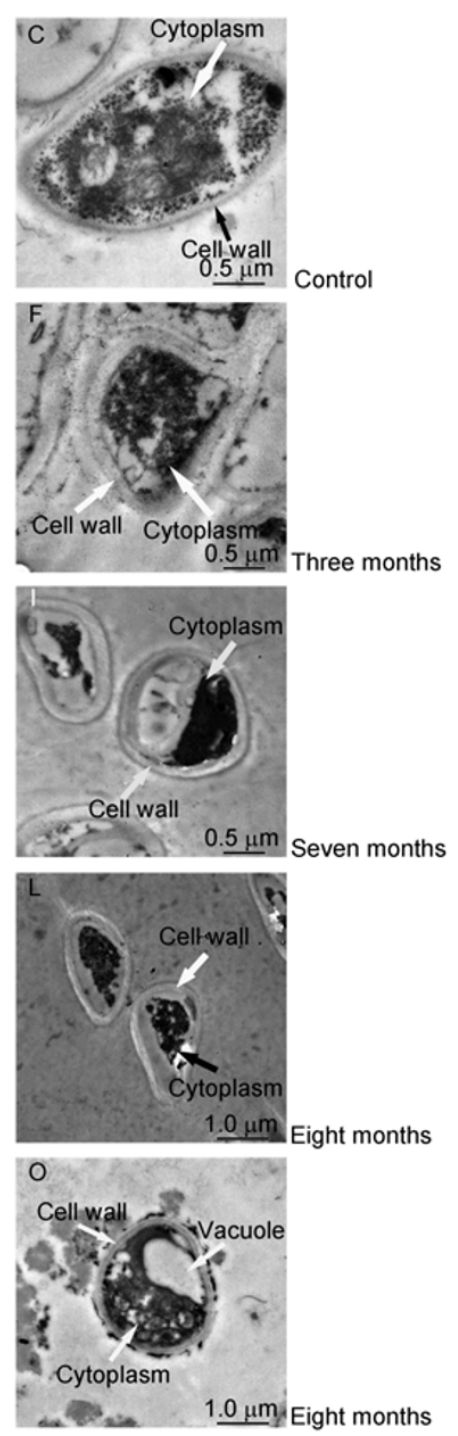

Figure 7 Comparative morphology and anatomy of isolated mycobiont under desiccation and starvation. SEM: A, control; D, after three months of combined desiccation and starvation; G, after seven months of combined desiccation and starvation; J, after eight months of combined desiccation and starvation; $\mathrm{M}$, after eight months of starvation alone. TEM (longitudinal section): B, control; E, after three months of combined desiccation and starvation; H, after seven months of combined desiccation and starvation; K, after eight months of combined desiccation and starvation; $\mathrm{N}$, after eight months of starvation alone. TEM (cross section): C, control; F, after three months of combined desiccation and starvation; I, after seven months of combined desiccation and starvation;

$\mathrm{L}$, after eight months of combined desiccation and starvation; O, after eight months of starvation alone. 
undergone some plasmolysis (Figure 7E and F). After seven months, the hyphae were strongly deformed into block and the stereoscopic hyphal contour was only visible in some places (Figure 7G). Hyphae had undergone obvious plasmolysis (Figure 7H and I). After eight months, hyphae were significantly deformed into plane block, stereoscopic hyphal contour was not visible (Figure 7J), and hyphae had undergone serious plasmolysis (Figure $7 \mathrm{~K}$ and L). After eight months of starvation stress alone, hyphae were still normal as compared with the control, but large parts of the hyphae were occupied by vacuoles (Figure $7 \mathrm{M}-\mathrm{O}$ ).

\subsubsection{Metabolic activity analysis of the mycobiont}

The metabolic activity of the isolated mycobiont was determined using fluorescence microscopy (Figure 8).

After being subjected to combined starvation and desiccation for 1-8 months, hyphae did not produce green fluorescence (Figure $8 \mathrm{~B}-\mathrm{E}$ ). After being subjected to starvation for eight months, hyphae in sterile distilled water produced green fluorescence (Figure 8F). Our florescence microscopy method was not sensitive enough to detect the metabolic activity of hyphae subjected to combined starvation and desiccation for 1-3 months. Hyphae subjected to starvation for eight months remained metabolically active. The starved but hydrated mycobiont clearly had greater survival capability after eight months than the starved and dried mycobiont after 1-3 months.

\subsection{Survival analyses of the phycobiont}

\subsubsection{Cell density measurement of the phycobiont}

The growth capability of the isolated $D$. chodatii phycobiont was determined by MNE (Figure 9) and CDM (Figure
10).

Colonies of phycobiont were scattered across the bases of the plastic Petri dish and were clearly visible after desiccation stress for one month (Figure 9B). None of the colonies was visible on the bottom of the dish after being subjected to stress for two months, but a greenish color was visible locally (Figure 9C). After three months of stress, no colonies or greenish color were visible (Figure 9D).

The cell density decreased rapidly when the phycobiont was subjected to desiccation, and almost no cell density was detected after three months (Figure 10).

These two results were basically consistent that the isolated $D$. chodatii phycobiont could maintain viability under desiccation stress for two months, and lose viability after three months.

After one month of desiccation stress, phycobiont cells had contracted with thick cellular contour (Figure 11D) and undergone some plasmolysis (Figure 11E and F). After two months, phycobiont cells had obviously contracted without thick cellular contour (Figure 11G) and undergone obvious plasmolysis (Figure $11 \mathrm{H}$ and I). After three months, phycobiont cells had significantly contracted without thick cellular contour (Figure 11J), and undergone serious plasmolysis and lysis of cell walls (Figure $11 \mathrm{~K}$ and L).

\subsubsection{Metabolic activity analysis of the phycobiont}

The metabolic activity of the isolated $D$. chodatii phycobiont was determined using FCM (Figure 12).

\subsubsection{Comparative morphological analysis of the phyco- biont}

The morphology and anatomy of the isolated $D$. chodatii phycobiont were observed using SEM and TEM (Figure 11).
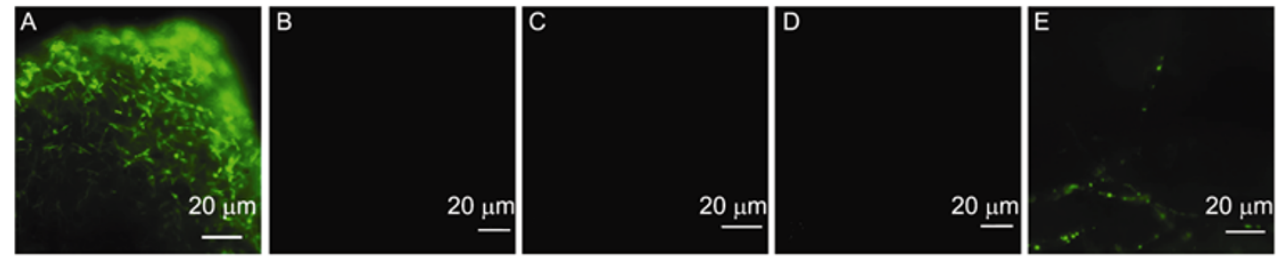

Figure 8 Metabolic activity of the isolated mycobiont under starvation and desiccation stress as detected by fluorescence microscopy. A, Control. B, After one month of combined desiccation and starvation. C, After three months of combined desiccation and starvation. D, After eight months of combined desiccation and starvation. E, After eight months of starvation alone.
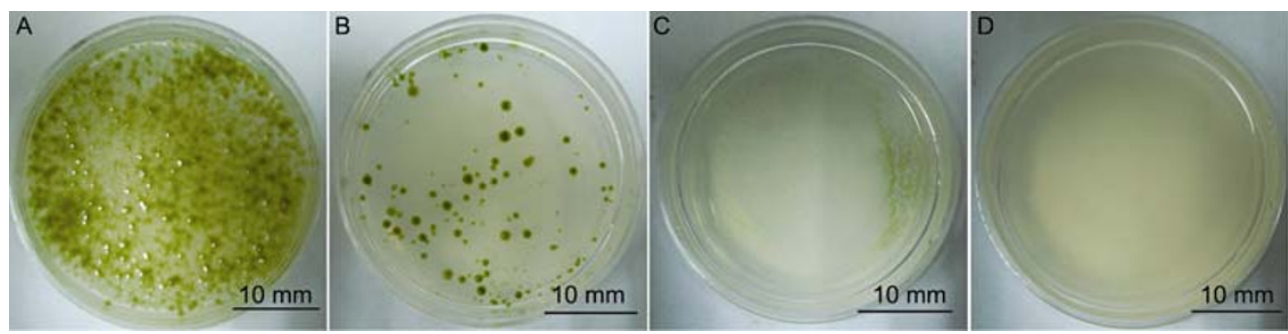

Figure 9 Colonies of the isolated D. chodatii phycobiont on PDA for two months after transferring from desiccation stress. A, Control. B, Transferred after one month of desiccation stress. C, After two months of desiccation stress. D, After three months of desiccation stress. 


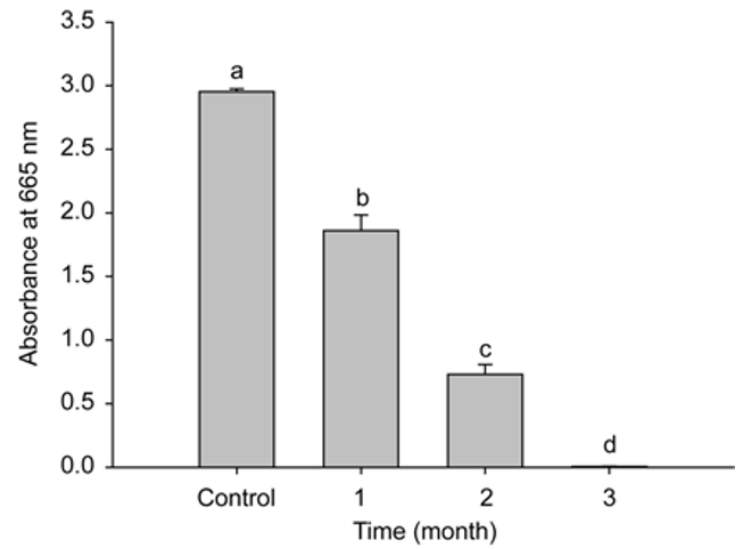

Figure 10 Cell density of $1 \mathrm{~mL}$ cell suspension from the isolated phycobiont $D$. chodatii grown on PDA for two months. Data are presented as mean \pm SD. Three replicates were analyzed for each. a, normal density; $b$, density reduced by nearly half; $c$, density reduced to $1 / 4$; d density reduced to zero.
Non-stressed phycobiont cells produced a low fluorescent signal if unstained with FDA (control; Figure 12A) and a high fluorescent signal if stained with FDA (control; Figure 12B). The number of green fluorescent cells decreased rapidly when the $D$. chodatii phycobiont was subjected to desiccation for 1-2 months, and almost no cells generated a fluorescent signal after three months (Figure 12C-E).

The results of metabolic activity analysis indicate that the isolated phycobiont $D$. chodatii can survive for two months under desiccation stress. D. chodatii demonstrates strong desiccation tolerance when compared with the other algae studied to date $[10,11]$.

Based on the above experiments, it appears that the survival time of mycobiont isolated from E. pusillum subjected to combined stress of desiccation and starvation was seven months, meaning that the starved mycobiont is able to maintain viability for seven months under drought
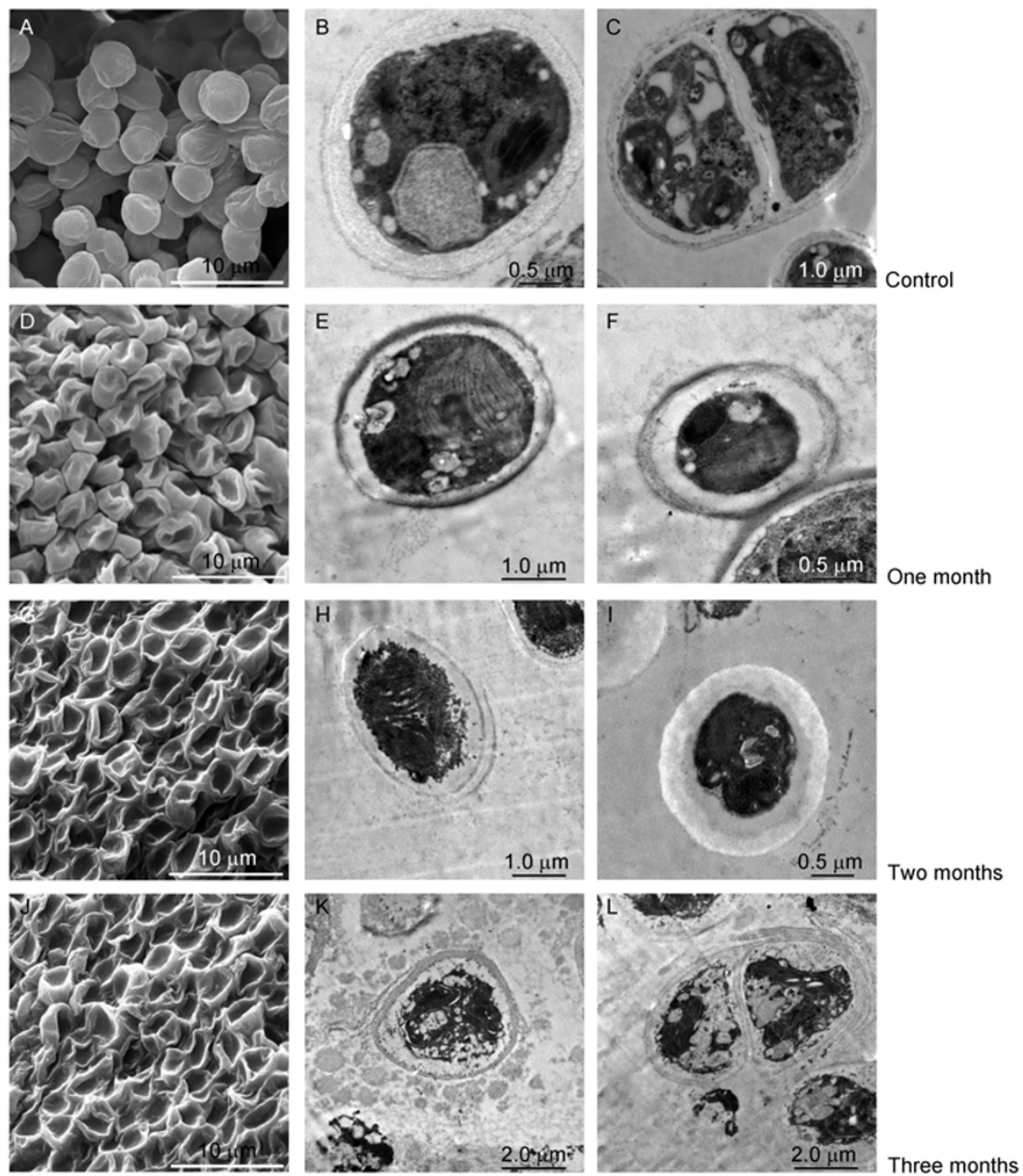

Figure 11 Comparative morphology and anatomy of isolated phycobiont under desiccation stress. SEM: A, control; D, after one month of desiccation; G, after two months of desiccation; J, after three months of desiccation. TEM: B and C, control; E and F, after one month of desiccation; $\mathrm{H}$ and I, after two months of desiccation; $\mathrm{K}$ and $\mathrm{L}$, after three months of desiccation. 

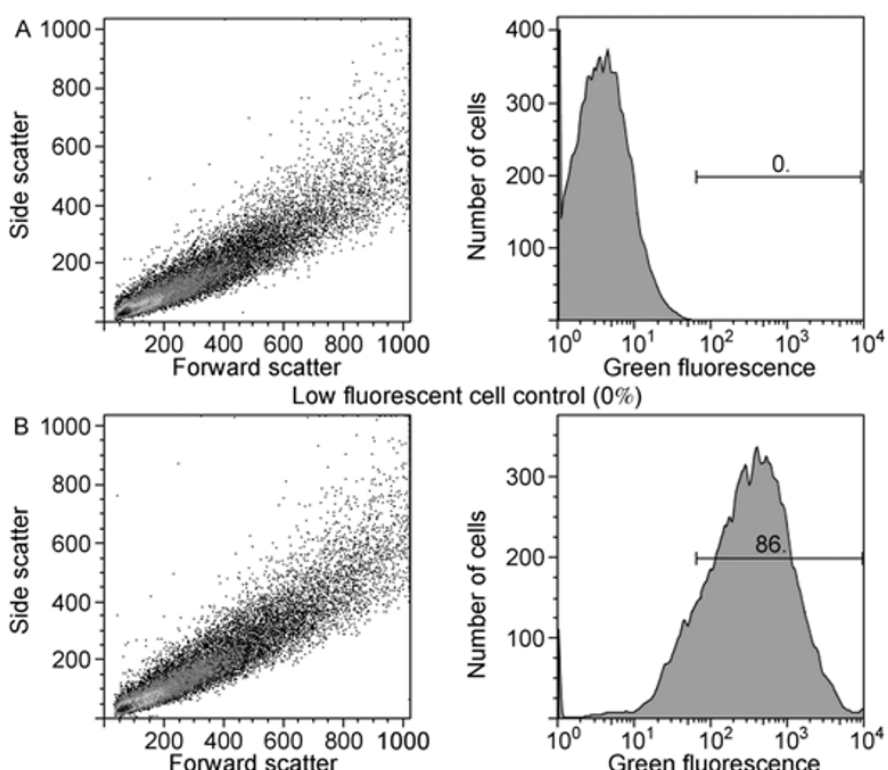

High fluorescent cell control $(86 \%)$
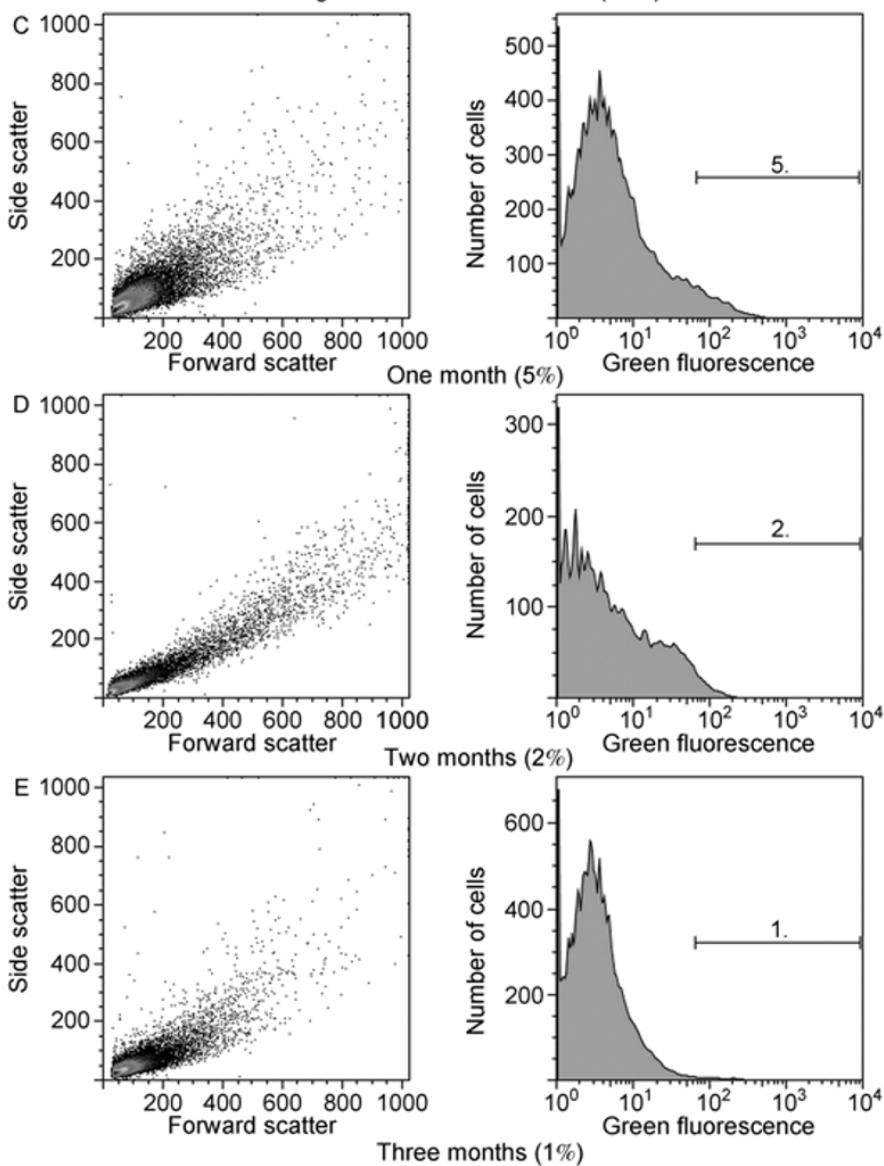

Figure $12 \mathrm{FCM}$ analysis of the isolated D. chodatii phycobiont. Each frequency distribution histogram corresponds to $3 \times 10^{4}$ cells analyzed. Two-parameter light scatter plots (forward scatter, FSC, depending on the cell volume; side scatter, SSC, depending on the inner complexity of the particle) and single-histograms of green fluorescence intensity are shown. A, Low fluorescent cells control. B, High fluorescent cells control. C, After one month of desiccation stress. D, After two months of desiccation stress. E, After three months of desiccation stress.

conditions. Such strong desiccation and starvation tolerance increases the chance of symbiotic contact between the mycobiont and its phycobiont in the arid desert in seven months, thus guaranteeing the ecological dominance of $E$. pusillum in desert regions.

The survival time of its phycobiont $D$. chodatii subjected 
to desiccation was only two months. However, both the synchronous release of mycobiont and phycobiont from the same lichen thallus after intermittent rainfall, and the existence of drought-tolerant mycobiont in nature tremendously increase the chances of the symbionts to form lichen E. pusillum and its reproduction in desert regions.

Our results provide a scientific basis for the arid desert biocarpet engineering to fix sand and carbon, which is accomplished by forming lichen crust through artificial cultivation and inoculation of symbionts isolated from $E$. pusillum in field, and also provide a referential desiccation time for drought-resistant genes that may be screened from this lichen mycobiont.

The further research will determine the survival limit of mycobionts subjected to the starvation stress for longer than eight months and that of mycobionts subjected to continuous rainfall for a period of six months or less in nature.

This work was supported by the National Natural Science Foundation of China (Grant No. 30670004) and Ministry of Science and Technology of China (Grant No.2007AA021405).

1 Lawrey J D, ed. Biology of Lichenized Fungi. New York: Praeger Publishers, 1984

2 Benkô Z, Juhász A, Pócs T, et al. Desiccation survival times in different desiccation-tolerant plants. Act Biol Szeg, 2002, 46: 231-233

3 Kranner I, Zorn M, Turk B, et al. Biochemical traits of lichens differing in relative desiccation tolerance. New Phytol, 2003, 160: 167-176

4 Lange O L. Hitze- und Trockenresistenz der Flechten in Beziehung zu ihrer Verbreitung. Flora, 1953, 140: 39-97

5 Becquerel P. Reviviscence du Xanthoria parietina desséché avec sa faune, six ans dans le vide et deux samaines á-189 ${ }^{\circ}$, Ses conséquences biologiques. C R Acad Sci, 1948, 226: 1413-1414

6 Ahmadjian V, Hale M E, eds. The Lichens. New York: Academic Press, 1973
7 Schaper T, Ott S. Photobiont selectivity and interspecific interactions in lichen communities. I. Culture experiments with the mycobiont Fulgensia bracteata. Plant Biol, 2003, 5: 1-10

8 Sterflinger K, Krumbein W E. Multiple stress factors affecting growth of rock-inhabiting black fungi. Bot Acta, 1995, 108: 490-496

9 Gorbushina A A, Kotlova E R, Sherstneva O A. Cellular responses of microcolonial rock fungi to long-term desiccation and subsequent rehydration. Stud Mycol, 2008, 61: 91-97

10 Agrwal S C, Singh V. Viability of dried cells, and survivability and reproduction under water stress, low light, heat and UV exposure in Chlorella vulgaris. Isr J Plant Sci, 2001, 49: 27-32

11 Gupta S, Agrawal S C. Survival of blue-green and green algae under stress conditions. Folia Microbiol, 2006, 51: 121-128

12 Yoshimura I, Yamamoto Y, Nakano T, et al. Isolation and culture of lichen photobionts and mycobionts. In: Kranner I, Beckett R P, Varma A K, eds. Protocols in Lichenology. Culturing, Biochemistry, Ecophysiology and Use in Biomonitoring. Berlin: Springer, 2002. 3-33

13 Li X R, Kong D S, Tan H J, et al. Changes in soil and in vegetation following stabilisation of dune in southeastern fringe of the Tengger Desert, China. Plant Soil, 2007, 300: 221-231

14 Cubero O F, Crespo A, Fatehi J, et al. DNA extraction and PCR amplification method suitable for fresh, herbarium-stored, lichenized and other fungi. Plant Sys Evol, 1999, 216: 243-249

15 White T J, Bruns T, Lee S, et al. Amplification and direct sequencing of fungal ribosomal RNA genes for phylogenetics. In: Innis M A, Gelfand D H, Sninsky J J, et al. eds. PCR Protocols: A Guide to Methods and Applications. New York: Academic Press, 1990. 315-322

16 Piercey-Normore M D, DePriest P T. Algal switching among lichen symbionts. Am J Bot, 2001, 88: 1490-1498

17 Saitou N, Nei M. The neighbor-joining method: A new method for reconstructing phylogenetic trees. Mol Biol Evol, 1987, 4: 406-425

18 Hadjoudja S, Vignoles C, Deluchat V, et al. Short term copper toxicity on Microcystis aeruginosa and Chlorella vulgaris using flow cytometry. Aquat Toxicol, 2009, 94: 255-264

19 Bialosuknia M W. Sur un nouveau genre de pleurococcacees. Bull Soc Bot Geneve, 1909, 1: 101-104

20 Heering W. Ulotrichales, Mikrosporales, Oedogoniales. In: Pascher A, ed. Die Susswasserflora Deutschlands, Osterreichs und der Schweiz, Heft 6, Chlorophyceae 3. Jena: G. Fisher, 1914. 51-53

21 Chodat R. Monographies d'algues en culture pure. Mat Fl Crypt Suisse, 1913, 4: 1-266

Open Access This article is distributed under the terms of the Creative Commons Attribution License which permits any use, distribution, and reproduction in any medium, provided the original author(s) and source are credited. 